\title{
THE FUTURE OF EQUITY PLANNING PRACTICE
}

\author{
Norman Krumholz and Kathryn Wertheim Hexter
}

\begin{abstract}
Equity planning tries to provide more choices for those who have few and to redistribute resources, political power, and participation toward the lower-income, disadvantaged residents of their cities. Early equity plans were adopted in several cities by official planning agencies. Since that time, equity planning has expanded beyond city planning departments and commissions. Social equity is now the primary focus of nonprofit community planning, regional planning, and other groups that use city planning techniques and often employ planners. They include community development corporations; public interest research groups (PIRGs); and groups working on the environment, access to healthy food, workforce development, and other issues. It seems clear that the most effective contemporary planning for social equity is now taking place within the community planning field, and the issues of sustainability, income inequality, and the diversification of our society suggest the probable expansion of equity planning in the future.
\end{abstract}

Equity planners have a professional obligation to bring the voices of the disenfranchised and disadvantaged to the decision-making tables. Contemporary city planners are professionals who deal with the physical form and function of cities: streets, parks, land use, and development, as well as zoning regulations of the physical city. Equity planners plan the physical city and also deal with policies and programs that address the social and economic conditions of city residents. In their day-to-day practice, equity planners deliberately attempt to move resources, political power, and political participation toward the lower-income, disadvantaged population of their cities.

The object of all planner's activities-whether consciously redistributive or not-is the form and function of cities and regions from neighborhoods and downtowns to transportation, from housing provision to the environment and economic development. Virtually all of the emphasis is placed on physical development. Cities continue to demand planning services, and outstanding students 
continue to be drawn to the planning profession because they want to help plan and build a more sustainable, just, and greener world. But actual planning practice in the bureaucracies of city hall, although essential, is often routine and uninspired. Planning could be much more than it is by expanding its scope and contributing to the resolution of inner-city problems like poverty, high unemployment, and poor health. This is part of the work in which equity planners are engaged; work which is making tangible contributions to the well-being of millions of human beings.

The concept of a more just society is not new to planning; it has always been there, but in recent years has been driven to the margins of the profession. Rising inequality and other well-publicized socioeconomic changes now challenge the neoliberal belief that a rising tide lifts all boats and make a powerful argument for a new emphasis on equity and justice.

This book examines the issues and modifications in urban planning practice and proposes changes that would strengthen the profession as an instrument of redistributive justice. Drawing from the real-world examples, it seeks to influence today's practicing planners as well as planning educators who are preparing the planners of the future. At the same time, it seeks to inspire future planners by demonstrating how the skills of planners to gather and synthesize relevant information and frame conclusions and recommendations have been used in cases around our country to support equitable outcomes. In these cases, planners have used their understanding of urban and regional structures and processes to address the pressing issues of our times- poverty, the deterioration of the environment and employment, the need to invest in infrastructure, and other crucially important matters. This book demonstrates how, at a time of impoverished governments, faltering economies, and federal neglect, planners have been freer to build alliances with collaborating organizations and propose their own equitable solutions, because everyone is looking for workable proposals that can make the most of resources they can tap.

Their guidelines are few but important.

\section{Guidelines for Equity Planners}

In general, equity planners are guided by a number of lessons and distilled values from their history. First, their work must be oriented toward the user; instead of basing the goals they seek on their own values, they must relate to the values and goals of the people for whom they are planning. A second lesson is related to the first: planners, no matter how wise, do not know all the answers; nor do the members of conventional boards, commissions, and councils. The breadth for 
whom planners and related professional bodies plan needs to be clear at the outset. Diversity is important, and people are entitled to live any way they choose so long as that way is not destructive to them or to their fellow citizens. Planners ought to respect their goals and objectives and provide people with the opportunity, resources, and freedom to choose what they want to do.

The third lesson is that genuine democracy in America cannot be achieved without much greater economic, social, and political equality, and this requires a concentrated attack on poverty and racial segregation. Most equity planners today believe that poverty and racial segregation are among the prime causes of the urban crisis and the major problems to be solved if the quality of urban life is to be improved for all the people in our cities. The Kerner Commission Report, although out of date and superseded by numerous books and research studies, provides the most candid indictment of racism and segregation seen in such a document before or since (Kerner et al. 1968). The Commission famously told America that our country was "moving toward two societies, one black, one white-separate and unequal" and urged an end to racial discrimination. The Commission also "identified residential segregation and unequal housing and economic conditions in the inner city as significant causes of ... social unrest," thus underscoring the report's contemporary significance. Recent events in Ferguson, Missouri, Baltimore, Chicago, Cleveland, and other cities make clear that the Commission's advice has gone largely unheeded, but America would be a different, and better, country had we taken seriously our responsibility to end racial segregation.

These three lessons have led to principles that guide equity planning today. Americans generally believe in advancing equality - at least in opportunity if not by right—as a civic value. Equity planners have incorporated that as a principle of their practice, believing that all plans and policies should be evaluated using the criterion of "who benefits, who pays." Planners should always pose the question of who are the least advantaged in any situation, and what would genuinely advance their life circumstances. Then planners should actively support those plans and policies that favor the disadvantaged as a matter of basic equity.

The fourth lesson of equity planning practice involves hope and persistence. Rather than an optimist or pessimist, the equity planner should be a "possible-ist"realizing that all things are possible under the right circumstances. What may seem impossible today becomes tomorrow's reality. Consider that in the 1980s, in one decade alone, the Berlin Wall fell, communism collapsed, and apartheid ended. More recently, in just a matter of years, gay and lesbian adults who endured a mismatch of half-rights in forming "civil unions" when seeking a legally sanctioned bond with their partners have now been accorded the full rights of marriage. The equity planner must have faith that change in the direction of a more equitable society is possible and that their work may contribute to that 
change. The planner must not hesitate to suggest plans and policies that are currently impractical or politically infeasible even though that may be the case. The institutions of society change constantly, but they change very slowly, and ideas that at first seem impractical become practical when the time is ripe. When good ideas are rejected, the equity planner must pick them up and put them back on the table to advance in new and different ways. If the planner demonstrates professional competence, argues the merit of ideas, and backs up their constructive recommendations with sound data and careful analysis, these suggestions may be adopted. More importantly, the equity planner knows that a steady diet of cynicism and self-doubt can be spiritually corrosive and politically enervating.

\section{Advancing Equity Planning}

A number of cities have adopted an equity planning approach in their planning and development activities. In the 1970s, Cleveland (under Mayor Carl B. Stokes) pioneered equity planning practice. In the 1980s, Chicago (under Mayor Harold Washington) did the same. Other cities-some with minority mayors as in Cleveland and Chicago, and others with white mayors like Boston, Denver, Hartford, Jersey City, Berkeley, and Santa Monica-also adopted an equityoriented approach to planning that included pressing for fair-share regional low-income housing schemes, increased accessibility to public transit for those without cars, rent control, broadened citizen participation, and other programs designed to aid lower-income residents. Liberal mayors are more likely to provide equity planners with essential support, but progressive planning ideas have also been implemented under more conservative political leadership (Krumholz and Clavel 1994).

More and more planners seem to be turning to equity-oriented planning, both at the official level and especially at the community level. Moreover, because of the events and changes in legislation and technology over the past fifty years, the future seems to hold promise of much more equity planning at all levelsdevelopments that have radically changed government and planning practice. The 1960s empowered the civil rights movement through the 1964 Civil Rights Act, the 1965 Voting Rights Act, and the 1968 Housing Act. The rights of citizens who would be directly affected by certain actions began to be protected and written into laws mandating citizen participation. The environmental legislation of the 1970s focused attention on protecting the natural environment and gave power to citizens to protect their quality of life (Rees 1995). The 1980s introduced concepts of environmental justice and sustainability, coupling the social objec- 
tive of equity along with environmental and economic concerns. Smart Growth and the New Urbanism of the 1990s integrated design into concepts of livability (Duany, Plater-Zyberk, and Speck 2000).

In 1991, Congress passed the Intermodal Surface Transportation Efficiency Act (ISTEA), which implemented dramatic changes. The law gave metropolitan regions great flexibility in how they spend transportation dollars while also mandating more transparency and accountability. It established stronger rules for public participation and required consideration of social issues, thus providing an opening to transportation decision making. President Clinton's Executive Order 12898 (1994) also ordered that federal agencies not adversely impact minority or lowincome communities. The first decade of the new millennium saw the rise in values associated with community health, food systems, and designs to encourage physical activity (Dill 2009, Kaufman 2004). In the 1970s and 1980s, the Internet was a novelty, and social media and "big data" were unknown. Within this expanding landscape, an equity planner could easily reconcile professional practice with the championing of their ideals, so long as the planner can be seen as speaking for the community.

These changes are being absorbed and adopted by traditional planning agencies, but they are also the primary focus of new nonprofit community planning groups that are multiplying rapidly. These groups represent urban planning activity outside the formal planning organizations of the city and state. Changes in laws over the past fifty years have given status and importance to nonprofit groups formerly excluded from the development process; these changes have enabled them to challenge development proposals and work on their own projects (Teitz 2014). Other nonprofits have emerged, including community development corporations (CDCs), green groups concerned with the environment, groups focused on access to healthy food, PIRGs, groups working on workforce and employment issues, comprehensive community initiatives, and others. Influenced early on by the pioneering support of the Ford Foundation for various initiatives tied to the War on Poverty in the 1960s and 1970s, they have been strengthened by HUD's HOPE VI and Sustainable Communities program, and these programs have awarded 143 regions with the resources to create equity plans. Also significant is the work of national intermediaries like the John D. and Catherine T. MacArthur Foundation, the Annie E. Casey Foundation, Local Initiative Support Corporation, and Enterprise Community Partners. Most of these organizations follow basic equity planning practices in their work, including extensive data collection and analysis. Most have planners on their staffs and reflect a new consciousness of social equity by creating new opportunities for equity planning.

The chapters in this book demonstrate that it is possible for planners to practice equity planning across disciplines and at all levels. The work ranges from rebuilding 
more equitable neighborhoods to reinvigorating federal programs and policies to serve the goals of equity and inclusion. In the following section, we summarize how these lessons have been applied and identify the strategies that have been successfully employed to increase choices for those who have few.

\section{Applying Lessons and Strategies Local}

The first section of the book offers lessons from local planners who are working outside of city hall and have been strong advocates for more equitable cities, neighborhoods, and communities. Lisa Bates, an academic, describes the struggle to include equity concerns related to affordable housing in Portland, Oregon's comprehensive land-use plan. Mark McDermott, a community developer, chronicles how equity planning principles and strategies shaped the community development sector in Cleveland. Majora Carter, an urban activist, tells her story of working in her home neighborhood of the South Bronx in New York through a dual focus on environmental equality and economic diversity.

Although working in very different settings, each author reoriented the planning conversations in their communities by shifting the narrative from planning by and for elites to planning by and for the deprived residents of the city. They set out to improve the quality of life for poor and near-poor residents by rebalancing the scales in land-use and development decisions to benefit those who have been negatively impacted by the political, economic, labor, housing, and health-care systems that continue to disadvantage these city residents, effectively locking them in "low-status" neighborhoods without access to political power or resources.

All used some variation of the traditional equity planning strategies of coalition building, leaking, and framing to move their agendas forward-sometimes successfully, and sometimes not. Lisa Bates describes the initial setbacks Portland's equity advocates faced in their attempts to include affordable housing and displacement as central platforms of the city's developing comprehensive land-use plan. She chronicles how she worked with community organizations to bring their own plan for affordable housing to the table and negotiated its inclusion into the official land-use plan. Yet, despite being presented with extensive data and analysis of increasing gentrification to help them make their case, city officials and planners were not on board. Equity advocates eventually succeeded in including measures to protect existing low- and moderate-income residents from gentrification by aligning with the statewide advocacy organization, 1000 Friends of Oregon, to argue for more affordable housing. They reframed the issue as a way to 
prevent displacement of existing residents and to preserve the Urban Growth Boundary. Joining with 1000 Friends amplified the voices and political clout of the equity advocates by giving them access to 1000 Friends' professional organizers, legal expertise in land use, and other needed resources to pressure reluctant city leaders and planners and, in some cases, give them the cover they needed to include equity in the land-use plan.

Mark McDermott documents the growth and maturation of the community development industry in Cleveland through his firsthand account of his own career as one of Cleveland's leading equity planners. As in Portland, community developers in Cleveland were focused on affordable housing and stability as a platform for achieving greater equity. They were also focused on race and acknowledged the role that decades of discriminatory race-based housing policies had in marginalizing poor city residents. Community developers were most successful when they formed strategic coalitions and partnerships with local officials, philanthropy, nonprofits, and universities; they also included local residents and did their homework, drawing on quality data and analysis with the understanding that research informs policy.

Majora Carter also uses as her starting point the intertwining of race and poverty. Her insights are especially revealing as she had grown up in and later returned to the South Bronx. She uses the term "low-status" communities to describe places like the South Bronx, where inequality is assumed as a given, even by those who live there. She offers a different perspective on the future of the neighborhood, now facing pressures brought on by gentrification. Although not a planner by profession, she thinks like a planner and takes the long view that neighborhoods are constantly changing.

Her place-based approach to managing that change utilizes a social entrepreneurship model of "self-gentrification" to promote a more economically diverse, equitable community that gives residents hope for a better future by staying in their own neighborhood. She uses surveys of residents and other organizing and engagement strategies to bring community voices to the table and raise awareness and to better frame issues in a way that resonates with residents. After learning what residents wanted and needed, she advocated for developing amenities and services that appealed to a range of income groups, thereby serving current residents while making the neighborhood attractive to new residents. She proposes a three-pronged strategy that involves reclaiming neighborhood control of land use, structuring real estate deals so that long-time neighborhood owners retain financial equity and benefit from any increasing property values, and promoting environmental equality. Like McDermott, her goal is to help minority communities build wealth and ownership and improve the quality of life. 


\section{Regional}

Section 2 of the book widens the lens of equity planning from the neighborhood/ local/nonprofit perspective to the regional perspective. Even neighborhood planners and those working for neighborhood-based nonprofits must be cognizant of the regional dynamics influencing the equity landscape. When central city neighborhoods and inner-ring suburbs become increasingly cut off from access to regional economic opportunities in jobs, housing, health, etc., the economy of the region declines as a whole. In short, regions with high levels of income inequality are less economically competitive.

Drawing from their experience of working in and studying seventeen metropolitan areas, Christopher Benner and Manuel Pastor offer insights for equity planning at the regional scale, while Todd Swanstrom offers an example of a successful transit-oriented development project that brought together twenty-four suburbs of the Normandy School District in St. Louis County and provided affordable housing for working-class households with access to a light rail line.

Benner and Pastor's chapter focuses on process. In the absence of a formal metro government structure or regional land-use and development planning organization, equity planners need to turn to the process of building "epistemic communities." This is a concept borrowed from international policy development that uses conversation and consensus building to work toward common solutions based on the identification of shared cultures, norms, and practices. They take the concept further, however, to describe communities that are diverse-able to include different ways of knowing — as well as dynamic — able to shift to address various challenges as they arise.

They cite several regions (e.g., Seattle, Salt Lake City, San Antonio) where such a process has resulted in policies designed to promote greater equity (such as a \$15 minimum wage), incentivizing development of affordable housing with transit access across the region, a fair-share affordable housing plan, and, perhaps most importantly, a set of regional indicators to track progress on equity. In addition, these successful regions also had a strong advocacy organization that served as a trusted source for information and policy analysis for various constituencies in the region (for example, the North Carolina Justice Center).

Swanstrom offers an example of a successful collaborative equity planning effort that involved the twenty-four high-poverty suburbs comprising the largely minority Normandy School District in St. Louis County, Missouri (including, notably, Ferguson). This is a case where none of the cities had a full-time planner on staff, so leadership on equity planning was provided by a nonprofit, "Beyond Housing" - another example of a strong advocacy organization, in this case one that was established to address the foreclosure crisis. Funded with a multimillion- 
dollar gift from an anonymous donor, Beyond Housing is a high capacity, trusted nonprofit. It commissioned a study, identified the need for housing for working families, and planned and developed a transit-oriented development project around a light rail station. The design of the development and the type of housing developed adapted in response to community input through a process facilitated by planners and organizers working for Beyond Housing. Although ultimately successful, the effort had its challenges, as it had to:

- Work across a highly fragmented local public sector that had little public money to invest.

- Institutionalize collaboration in fragmented suburbs and form alliances with central cities.

As efforts to address growing inequality increasingly turn to the regional scale and as poverty rates increase in suburban areas, equity planners are just as likely to be working at the regional scale. As noted above, the focus on sustainability, which views equity as its core foundation, along with economic and environmental concerns can be an effective way to bring equity into regional discussions. Recent regional planning efforts, including those led by the Obama administration to encourage cross-agency and cross-sector collaborative planning, have focused on fair and affordable housing, land use, transportation, jobs, and environmental considerations with mixed results.

\section{National}

The four chapters in this section offer a national policy perspective on issues of equity in transportation, workforce, housing, and planning for an aging population. Joe Grengs argues for the primacy of access over mobility with regard to transportation planning as a way to expand opportunity and promote a wider range of living and working choices for those who have few. Robert Giloth addresses the ever-present need for a more equity-oriented approach to increasing the number and quality of employment opportunities for black men and communities of color, even as wages and the quality of jobs are being eroded. He calls for shifting the focus from the traditional growth model to a focus on access to good jobs, the retention of manufacturing, neighborhood economic development, and investment in human capital and workforce training. Patrick Costigan offers an instructive case study of how the federal government, faced with a failing public housing system resulting from decades of disinvestment and indifference to the conditions in which residents were living, sought to restructure the system to infuse much-needed capital into revitalization and to make a wider array of choices available to public housing residents. In the final chapter of this section, 
Deborah Howe makes a compelling case for planners to take a much more active role in providing meaningful housing, transportation, and lifestyle choices for the rapidly growing aging population.

In these cases, providing valid choices for those who have few means understanding the needs of the population in need, adopting public policy based on that understanding, and building that need into public policy. In the area of transportation planning, Grengs provides a way to target transportation services to compensate for disadvantages in other areas. He prioritizes serving the least advantaged first by designing transportation systems to provide them with the freedom and capacity to choose among a variety of options to gain access to jobs and other necessities such as health care. He offers a range of strategies to accomplish this:

- Strengthen public engagement, especially of marginalized populations.

- Replace a mobility-based framework with an accessibility framework; promote accessibility to be the fundamental metric and demote mobility in the hierarchy of importance. Mobility matters, but merely as one among several means to accessibility, which should be the end goal.

- Adopt a more explicitly normative position to seek to redress preexisting disadvantages by strategically redirecting transportation benefits to those in greatest need; bring transportation analysis in line with the Federal Transportation Law adopted by Congress in 2012 that treats accessibility as the primary and only measure of effectiveness.

- Improve analytic capabilities to reframe decision making to achieve higher levels of access.

- Develop measurement tools that link social equity and the built environment; look outside the box to new transportation solutions, such as driverless cars and shared mobility, as well as nontransportation solutions, such as changing land-use regulations to improve not only the proximity of destinations but also individual characteristics, such as income or an individual's capability of using a car, for example, to get where you need to go. Accessibility is an attribute of people or households, not places or infrastructure; the onus is on the planner to identify those people and places most in need and redirect resources.

- Advance transportation policies that broaden the scope of choices.

In the workforce arena, equity planning has always included a focus on jobs and opportunity but discrimination persists. In fact, Giloth calls for a new civil rights movement with a focus on jobs and careers as a foundation of full citizenship. How can equity planners change entrenched, discriminatory systems to open up labor markets and improve job quality (i.e., jobs with family supporting in- 
comes and a career pathway)? They cannot do it on their own. It requires progressive political leadership at the state and local level along with supportive federal policies. He proposes a multipronged strategy-working at levels of system change, policy, planning, and organizing that involves the traditional "workforce" areas of manufacturing retention, neighborhood economic development, human capital, and workforce investment as well as education, transportation, and affordable housing so that transit dependent populations can reach job centers or afford housing near job centers. Giloth offers a number of examples of places that have used Community Benefit Agreements (CBAs) and economic inclusion plans, micro lenders, cooperative businesses, and impact investing to achieve greater equity in workforce systems at the regional scale. He also gives examples of successful long-term civic collaboration and leadership from sector partnerships (work groups of companies to spread risk across firms) and anchor institutions ("eds and meds")—changing hiring practices, using CBAs for construction projects, using local purchasing to grow local jobs in local businesses, promoting small local businesses and entrepreneurship, and working toward greater equity at the regional scale.

In the area of federal housing policy, Costigan traces the development and implementation of the Rental Assistance Demonstration program to address funding shortfalls in public housing. In 2009, faced with decades of declining funding, legislative indifference, and a structural $\$ 26$ billion backlog in public housing capital repairs, the U.S. Department of Housing and Urban Development pursued change that would enable it to provide more housing options for public housing residents. The recession that triggered the collapse of the housing market also resulted in the greatest stripping of wealth from African American homeowners (most of whom have still not recovered) and provided the impetus to advance an equity-oriented public housing agenda. It took a crisis, committed and determined leaders, and the patient building of a diverse constituency to reform public housing. Using the traditional equity planning skills of vision, careful analysis, advocacy, and coalition building, HUD's leadership was able to implement a pilot program, the Rental Assistance Demonstration (RAD), that leveraged $\$ 19$ of private capital for every $\$ 1$ of HUD funding to revitalize eighty-three thousand units of public and assisted housing. Equally importantly, RAD gave participating public housing authorities the ability to budget and maintain long-term replacement reserves that can be used to upgrade properties and slow demolition.

As our population rapidly ages, Howe makes the case for using public dollars, building codes, accessory dwellings, universal design, transportation alternatives, and road design to transform the built environment to be aging supportive. In this way communities will be better positioned to meet the needs of elderly and 
nonelderly residents. Following a basic tenet of equity planning, she argues for including the elderly in planning decision making (however, avoiding pitting one generation against another) and building coalitions with advocates and experts (e.g., AARP, Robert Wood Johnson Foundation).

As these authors point out, changing entrenched systems at the national level is difficult work. There are powerful interests that benefit from the status quo. Funding for programs that benefit the most disadvantaged is declining, and the political landscape is in flux. The chapters in this section offer ways to work within existing systems, as well as ways to change the systems.

It is the planner's job to take the long-term view. For the aging, this necessitates not only building aging issues into plans but also implementing those plans to address the special challenges of aging (e.g., lifecycle communities or lifelong communities). For workforce, it involves embracing technological change and more transformative discussions about the future of work which call into question whether employment as an equity goal is even plausible. Future planners will need traditional planning skills, such as community organizing, coalition building, and conflict management. As they plan for today's workforce, they will also need vision and imagination to conceive of new and innovative "on-ramps" for individuals seeking employment (such as social enterprises) and a new social compact of income and work supports for a postwork society.

\section{The Future}

The final section of this book looks to the challenge of preparing future generations of equity planners to respond to rapidly changing urban environments and to new technology. Reardon and Forester draw from their forty years of experience teaching equity planning to offer some best practices, including exposing students to hands-on learning opportunities and offering tools and techniques to prepare future planners to prioritize equity in their professional careers. Thompson and Arceneaux provide a case study of planners using technologyenhanced tools such as public participation geographic information systems (PPGIS) to enable citizens to participate more effectively in planning for their own neighborhoods.

In educating future planners, it is not enough to offer equity planning courses or to include considerations of equity in the curriculum. Forester and Reardon describe effective techniques and enhancements to explicitly prepare students to prioritize the needs of disadvantaged populations. Students need techniques for promoting joint problem solving, such as co-generated research (providing expert analysis not FOR users but WITH users), urban ethnography (which encompasses a close and respectful working relationship with the community), 
internships to incorporate hands-on learning opportunities, participatory action research, experience organizing for resident-driven problem solving or community responsive public planning processes, coalition and network building, and social media usage to promote citizen participation. Curriculum enhancements include incorporating area studies of cultural identity groups, providing a more rigorous introduction to urban and metropolitan politics and community organizing, strengthening the commitment to diversity in students and faculty as well as in scholarly publications, and addressing unexamined white privilege and institutional racism and how it has shaped urban areas.

As Reardon and Forester point out, the good news is that, in the forty years since Krumholz and his colleagues wrote the first equity plan, equity planning has become an essential element of mainstream planning education. Yet, over that same time period, America's cities have changed dramatically, becoming even more segregated and unequal. And they are poised for a major transformation in the future as driverless cars and other smart technologies change the form and function of the urban landscape. At the same time, at least for the foreseeable future, fewer public resources will be available. Under these circumstances, ensuring that those with the fewest choices are not harmed further and preferably benefit from these changes will be a significant challenge facing future planners.

Another trend that is shaping how planners work is the increasing availability of open source data. According to an article in CityLab (Bliss 2017), more than one hundred American cities host online open data portals where planners and citizens can find data on crime, housing, transit, etc. Ideally, this data offers citizens a way to plan for their own neighborhoods and to hold governments accountable for outcomes. In practice, it is quite difficult for nonexperts to access this data and make sense of it. Planners are uniquely positioned to serve as intermediaries and to use their expertise in data and geospatial analysis to work with community organizations and residents to help them visualize the geographic implications of data and develop community plans.

Thompson and Arceneaux's chapter describes how they used one such geospatial technique, Public Participation Geographic Information Systems (PPGIS), to enable neighborhood residents to have a greater voice in planning for their New Orleans neighborhoods, post-Hurricane Katrina. In 2011, the authors-part of a group of professional and student volunteers from the University of New Orleans's Department of Planning and Urban Studies_-began to use PPGIS to work with neighborhood associations to enable them to collect, map, and quantify quality-of-life challenges faced by residents. They used PPGIS to facilitate the use of big and small data by nonprofits. This tool gave neighborhood residents control over their own community narrative to guide equitable neighborhood recovery. 
Their chapter points out the promise of democratizing data, as well as its challenges: local political agendas that may not coincide with citizen agendas; sustaining citizen participation over the long term; finding volunteers who live in a neighborhood, especially one that has been devastated by natural (hurricanes) or man-made (foreclosures) disasters; and concerns with the accuracy, validity, and utility of crowdsourced data. Furthermore, local government can pose a barrier by not sharing data either within the city across departments or with the public. Finally, PPGIS can be a resource for citizen decision making but does not necessarily provide a platform to catalyze policy change. Planners need to understand data management and ethics, share their expertise, and work with residents to provide ongoing support to track progress as plans are implemented to keep public officials accountable.

\section{Barriers to Equity Planning}

Equity planners need to be realistic. A frequent critique among planners is that even if they are able to prioritize benefits to disadvantaged populations in their plans and policy recommendations, they have little influence over whether or not plans are implemented; the adoption and implementation is often in the hands of politicians. The lack of political support and other external factors can be barriers to equity planning, but other barriers are internal to the planners' personal approach. Equity planners need motivation, confidence, and the will to change prevailing ideas, especially in cities without progressive political leadership.

They also need a firm grasp of the tools (illustrated throughout this book) that can be used to build constituencies for adopting and implementing plans and used to give politicians the cover they need to make the decisions that many of them would like to make-specifically, data-driven analysis, organizing and public engagement, coalition building, leaking, framing, and holding public officials accountable.

These tools will be especially useful during this time of retrenchment of federal funds and programs. Changes to policies and regulations that protect the poor and threats to immigrant and religious and ethnic minority communities and the full array of destabilizing forces will result in increasing inequality.

Since the 1970s, the equity-oriented work of city planners has some produced tangible benefits for poor and working-class city residents. It has done so even in the face of increasing levels of inequality, prevailing norms, institutional bias, and the complicated issues of race and diversity. However, much more needs to be done.

This book illustrates that equity planners no longer work exclusively for local governments. They can be increasingly found working for nonprofits, at philan- 
thropies with public interest agendas, and in state and national government. They are also no longer exclusively involved in developing city plans. For all those who see their work as equity planning or who aspire to be equity planners-at every level and in every sector-this book is as much a "call to action" as it is a "how to."

It seems clear that the most effective contemporary planning for social equity is taking place within the community planning field. This is not true for all community-planning organizations, as they retain a spotty track record across geographies and organizations. Yet there are many community-planning organizations that are creating the space for the nexus of equity planning and equity implementation. These high-performing organizations are inviting authentic resident participation, leading coalitions and partnerships with state and local governments, creating new capital solutions that are reliant on multiple sources of funding, and driving policies focused on localized community benefit. None of these functions are new to the world of planning and community development. But it seems clear that the evolution of community planning is built on the foundation of social equity as its principal intention, and this evolution is moving faster and reaching deeper than realized, promising an upsurge of equity planning in the future.

It also seems clear that the boundaries of community-based planning are expanding rapidly. Trying to make the most of their limited resources, CDCs are turning to large, specialized, nonprofit national corporations like BRIDGE Housing and the Community Builders as a means of going to scale. Others, like the well-known Harlem Children's Zone in New York City, have education at their core; health care, as in Boston's Codman Square Health Center, is another entering wedge for community development.

At the same time, there is evidence of renewed attention to equity in cities across the country. Recently, for example, the mayor of Houston, Texas, created an equity task force to make recommendations for rebuilding the city after Hurricane Harvey (2017). The recommendations include setting goals and metrics for tracking progress in broad areas such as minimum wage, housing, transportation, and employment. The National League of Cities has a tactical team in place to provide cities with technical assistance and training in support of a racial equity plan.

\section{What's Next for Equity Planning?}

There are three reasons to expect a new upsurge of equity planning in the future: (1) the evolution of the environmental sustainability movement in the context of urban planning and development; (2) the increasing concern for socioeconomic inequalities; and (3) changes in national demographics. 
Social equity is one of the "Three Es" that are central to the sustainability movement; the others are environmental integrity and economic prosperity. Sustainability is a well-known concept in urban planning, but it is now conceived with new urgency-the idea being that everyone in the community needs the opportunity to participate and thrive for that community to sustain itself.

Until the 1990s very little of the sustainable development literature focused on cities or patterns of urban development. Instead, writers discussed the crisis caused by the exponential explosion of the population worldwide, the global environment, and the need for a transformation of values favoring conservation over growth. However, in more recent years, planners and architects have begun looking more specifically at how the "Three Es"-economic development, environment, and social equity - translate into patterns of city and metropolitan development (Wheeler 2013). Some authors have emphasized urban design and physical planning and development. Others have focused on environmental planning concerns having to do with the quality of air, water, and natural ecosystems. But a significant number have also noticed the need to address social problems and inequities within the urban community, and they have emphasized the point that environmental and social issues are inextricably linked. In all of these categories, urban sustainability advocates can be seen as building on the work of past planning visionaries such as Patrick Geddes, Ebenezer Howard, Jane Jacobs, and RPAA members Lewis Mumford and Ian McHarg. We see this both in the movements for sustainability and the related push for green cities.

Some of the main directions for urban sustainability include the following: efficient land use, efficient resource use, sustainable economics, good housing and living environments, the lessening importance of the automobile, a healthy social ecology, and community participation. As noted above, these elements have been simplified into what is generally referred to as the "Three Es" (Campbell 1996). In practice, the application of sustainability is often full of intractable conflicts with implementation that favors one principle over the others—often with social equity having a lower priority (Conroy 2006). It is often called the "stealth" principle. But urban planners should always advocate for social equity. It is their unique contribution to public policy and a mandate of the profession. If planners wish to change the world for the better, social equity should be their highest priority, even if it clashes with other important values (Beatley and Manning 1997).

Green urbanization is also not a new idea. Before World War I, Patrick Geddes had classified the environmental needs of different ecological systems and developed a systematic approach to building cities that respected natural systems. Ian McHarg's book Design with Nature (1969) inspired the environmentally conscious generation of the 1960s. Today, respect for the natural environment is the cornerstone of the New Urbanism movement. The future will see the evolution 
of green development standards having to do with compact land-use patterns, regional green space designs, solar installations, and green roofs to conserve energy. Environmental justice issues will also be in the mix to ensure that the needs of the poor are taken into consideration. This is especially true in light of Pope Francis's important 2015 encyclical Laudato Si that points out the deleterious impact of global warming on poor populations around the world. The Pope's message is an unusual melding of science with faith and calls for a radical transformation of politics, economics, and individual lifestyles to confront environmental depredation and climate change. It is a powerful message in support of a more sustainable and equitable world.

Just as the Three Es of the sustainability movement provide support for the assumption that more equity planning is likely for the future, so too does the rising concern for socioeconomic inequality. Inequality of income, wealth, and opportunity in the United States is high compared to other developed democracies, and the gap appears to be growing.

Perhaps most significant for an expanded equity planning practice in the future is the change in our national demographics, making for a more pluralistic society. A recent census bureau report makes clear that by 2044, whites will no longer make up a racial majority in the United States (Frey 2015). By then, the nation-like today's Los Angeles-will be made up of a kaleidoscope of racial groups, including Latinos, blacks, Asians, Native Americans, and multiracial Americans. In just sixteen years from 2015 there will be minority white populations in twelve states, including California, Texas, Florida, New York, Georgia, and New Jersey (Teixeira et al. 2015). It is a change that does not depend on immigration; it is already here and thriving among children younger than five and among all students in the nation's public schools. It is a change that should be welcomed since it will help our country to prosper.

This diversity boom is a godsend, occurring in time to counterbalance the aging of our white population; this may give the United States a chance to avert the problems of a stagnating and aging population which Japan, Italy, and other European nations are already facing. We are gaining a competitive advantage, and our priority should be to integrate immigrant and native-born minorities, provide necessary social and education services, and prepare the younger members for success.

This increased diversity will produce political conditions that make a more liberal response possible, not only in planning, but in all the institutions of American society. Our diversifying population has already elected more minorities at every level of government than ever before. This process seems likely to continue as political leaders see the potential for a new and more liberal coalition to upset traditional alignments. This coalition will come under powerful pressure from 
the opposition trying to hold onto its power. The opposition will attempt to keep coalition members from voting while trying to subvert and scatter its membership. They will do so through voter ID laws, racial gerrymandering, mass disenfranchisement through the criminal justice system, and other devices. They will try to exploit the divisions of culture and class that exist between ethnic groups which are acute in some cities like Los Angeles (Jackson and Preston 1994). But leaders will be found to overcome these powerful impediments.

The elected leaders of this coalition will not govern in the same way, but they will all try to hold their coalition together and do more for their political base. They will work to increase voter participation, broaden the range of opportunities available to all, moderate inequality through a redistributive tax system, encourage union representation, and implement large-scale initiatives in infrastructure, education, and research. With stronger political support, planners will rediscover the concepts of advocacy, pluralism, and justice and relearn the progressive lessons of their own history.

The editors and contributors to this volume assumed that while leadership at the federal level would change from time to time, it would continue to be, if not supportive, at least tolerant of the ideas put forward by equity planners. But what if this assumption proved to be incorrect, and planners could no longer count on a benevolent federal government? The possibility of a hostile federal government was apparent to at least some observers as indicated by a passage from Richard Rorty's 1998 book, Achieving Our Country. Rorty, a philosopher who died in 2007, predicted that the neglected working class would not tolerate its marginalization for long. "Something will crack," he wrote:

The non-suburban electorate will decide that the system has failed and start looking around for a strongman to vote for-someone willing to assure them that, once he is elected, the smug bureaucrats, tricky lawyers, over-paid bond salesmen, and postmodernist professors will no longer be calling the shots.... One thing that is very likely to happen is that the gains made in the last forty years by black and brown Americans, and by homosexuals, will be wiped out. Jocular contempt for women will come back into fashion.... All the resentment which badly educated Americans feel about having their manners dictated to them by college graduates will find an outlet. (Rorty 1998)

In November 2016 the neglected working class found their man in Donald J. Trump and reacted with an impact that will pass through legal and administrative systems, changing the way planners and others approach their responsibilities. Once in office, President Trump and his party immediately began to try to turn back the clock. 
What strategies should progressive planners and others follow given this event? First, they should try to do everything possible to protect their cities from crucial budget cuts. This means fighting to maintain adequate levels of funding for housing, education, public transit, infrastructure, and the social safety net, all of which contribute to a functioning, cohesive society. Second, they can organize protests, support investigative reporting, and write op-eds exposing counterproductive policies. Third, planners can join the people in the streets. Given President Trump's history with African Americans, Muslims, Latinos, unionized labor, gays, people with disabilities, and other groups, there is likely to be plenty of protest; it may be that democracy will thrive in the streets as it did in the 1960s.

It would also seem that turning to institutions closer to home would constitute a proper reaction. To a large extent, these institutions are what secure and sustain our values. It is time to strengthen these institutions. Most Americans believe in and support fair-minded journalism, scientific discovery, scholarship, and the arts. Many local municipalities and state governments are eager to work on the hard problems-whether it's making sure people have a roof over their heads and enough to eat, or get proper care when they get sick, or that wages are lifted, or that the reality of climate change is addressed. States like Massachusetts will continue to implement its popular comprehensive health insurance plan, and California, with its determination to address climate change, will persevere regardless of federal resistance. Other states will follow their lead.

Closer to our daily lives are institutions like hospitals and schools. These institutions have evolved their own ethics in keeping with American ideals and will continue to protect their values regardless of the changes that take place at the federal level. If the people in Washington make bad judgments, these smaller-scale institutions that directly impact people's daily lives will check the consequences of those choices. The test is whether the gap between what we preach and what we practice shrinks or expands. The job of equity planners and others of good conscience will be to hold those in power to account for that result, and that includes the future of all those left out and left behind. Reason and compassion demand no less.

\section{REFERENCES}

Beatley, Timothy, and Kristy Manning. 1997. The Ecology of Place: Planning for the Environment, Economy, and Community. Washington, DC: Island Press.

Bliss, Laura. 2017. “An Open Data Hub That Builds Better Citizens.” CityLab. https:// www.citylab.com/solutions/2017/07/an-open-data-hub-that-builds-better -citizens/533217/.

Campbell, Scott. 1996. "Green Cities, Growing Cities, Just Cities? Urban Planning and the Contradictions of Sustainable Development," Journal of the American Planning Association 6 (2): 3 . 
Conroy, Maria Manta. 2006. "Moving the Middle Ahead, Challenges and Opportunities of Sustainability in Indiana, Kentucky and Ohio," Journal of Planning Education and Research 26 (1): 18-27.

Curry, Robert. 2015. Personal correspondence with the author.

Dill, Jennifer. 2009. "Bicycling for Transportation and Health: The Role of Infrastructure," Journal of Public Health Policy 30 (Suppl. 1): 95-110.

Duany, Andres, Elizabeth Plater-Zyberk, and Jeff Speck. 2000. The Rise of Sprawl and the Decline of Nation. New York: North Point Press.

Executive Order 12898. Federal Actions to Address Environmental Justice in Minority Populations and Low-Income Populations. 1994. 59 FR 7629 (February 16). https:// www.epa.gov/laws-regulations/summary-executive-order-12898-federal-actions -address-environmental-justice.

Frey, William F. 2015. Diversity Explosion: How the New Racial Demographics Are Remaking America. Washington, DC: The Brookings Institution.

Grengs, Joe. 2002. "Community-Based Planning As a Source of Political Change: The Transit Equity Movement of Los Angeles' Bus Riders Union," Journal of the American Planning Association (68) 2: 165-78.

Huang, Joyce. 2015. "National Scan of Existing CBAs." Unpublished document. Center for Community Planning and Development, Cleveland State University.

Jackson, B. O., and M. B. Preston. 1994. "Race and Ethnicity in Los Angeles Politics.” In Big City Politics, Governance, and Fiscal Constraints, edited by G. E. Peterson. Washington DC: Urban Institute Press.

Kaufman, Jerome L. 2004. "Introduction," Journal of Planning Education and Research 23 (4): 333-34.

Kerner, Otto et al. 1968. Report of the National Advisory Commission on Civil Disorders. New York: Bantam Books.

Krumholz, Norman. 1997. "The Provision of Housing in Cleveland: Patterns of Organization and Financial Support." In Housing and Urban Development in the United States, edited by Willem van Vliet. Thousand Oaks: Sage.

Krumholz, Norman, and Pierre Clavel. 1994. Reimagining Cities: Equity Planners Tell Their Stories. Philadelphia: Temple University Press.

Labor/Community Strategy Center v. Los Angeles County Metropolitan Transit Authority. 1996. 2:94-cv-5936 (C.D. Cal.), Consent Decree.

Levine, Amy. 2009. “Community Benefits Agreements.” Accessed October 2009. http:// www.communitybenefits.blogspot.com.

Rees, W. E. 1995. “Achieving Sustainability: Reform or Transformation?” Journal of Planning Literature 9 (4): 343-61.

Rorty, Richard. 1998. Achieving Our Country. Cambridge: Harvard University Press.

Teixeira, Ruy, William H. Frey, and Rob Griffin. 2015. "States of Change: The Demographic Evolution of the American Electorate, 1974-2060," Center for American Progress.

Tietz, Michael, and Karen Chappel. 2012. "Planning and Poverty: An Uneasy Relationship." In Policy, Planning, and People: Promoting Justice in Urban Development, edited by Naomi Carmon and Susan Fainstein. Philadelphia: University of Pennsylvania Press.

Wheeler, Stephen. 2013. Planning for Sustainability: Creating Livable, Equitable, and Ecological Communities. New York: Routledge.

Wolf-Powers, Laura. 2010. "Community Benefits Agreements and Local Government," Journal of the American Planning Association 76 (2): 141-59. 